\title{
Epidemiologic profile of oral squamous cell carcinoma in Yogyakarta, Indonesia
}

\author{
Isadora Gracia*,Totok Utoro**, Supriatno***, Indwiani Astuti****, Didik Setyo \\ Heriyanto*****, Dibyo Pramono****** \\ *Department of Oral Medicine Faculty of Medicine Universitas Katolik Atma Jaya \\ **Department of Anatomic Pathology Faculty of Medicine Universitas Gadjah Mada \\ *** Department of Oral Medicine Faculty of Dentistry Universitas Gadjah Mada \\ ****Department of Pharmacology Faculty of Medicine Universitas Gadjah Mada \\ ***** Department of Clinical Pathology Faculty of Medicine Universitas Gadjah Mada \\ ******Department of Community and Preventive Dentistry Faculty of Dentistry Universitas Gadjah \\ Mada
}

\begin{abstract}
Introduction: Oral cancer is a major health problem in the world, indicated by a high incidence of recurrence. In Southeast Asia, oral cancer ranks sixth from all cancers on the human body. The incidence of oral cancer, especially squamous cell carcinoma types, increases every year, but the prognosis and patients life expectancy are still unsatisfying enough and the reports about the profile of oral cancer is still limited.The objective of this research was to get the epidemiological profile of oral squamous cell carcinoma (OSCC) in Yogyakarta, Indonesia. Methods: The research method was observational analytic with cross-sectional design. All new OSCC cases in three anatomic pathology laboratory installations in Yogyakarta (January 2011-December 2015) were included in this study. Data collected were gender, age, anatomical location, and histology. All data were analyzed using statistical analysis program. Results: OSCC new cases amount increasing each year: 6 cases $(6.6 \%)$ in 2011, and increased to 24 cases (26.4\%) in 2015. Fifty-two of the 91 cases $(57.1 \%)$ were found on male. The age group with the most cases was found in group of $41-60$ years (49.5\%). There is no difference in the case distribution by age between male and female. Forty-eight cases were found in the lingual part (52.7\%). Histological examination showed 68 cases $(74.7 \%)$ were well-differentiated carcinoma. Conclusion: OSCC profile in Yogyakarta mostly found in men with anatomical location in the lingual part in the age group above 40 years of age and were having well-differentiated histology.
\end{abstract}

Keywords: Oral squamous cell carcinoma (OSCC), Epidemiologic profile, Yogyakarta

P-ISSN 1979-0201, e-ISSN 2549-6212 Available from:http://jurnal.unpad.ac.id/pjd/index

DOI:http://dx.doi.org/10.24198/pjd.vol29no1.11614

Submission: Jan 2017 Publishing: March 2017

Corresponding author: Isadora Gracia, Department of Oral Medicine Faculty of Medicine Universitas Katolik Atma Jaya Jl. Jend. Sudirman No.51, RT.5/RW.4, Karet Semanggi, Setia Budi, DKI Jakarta 12930 


\section{INTRODUCTION}

Oral cancer is a major health problem in the world. From the data taken from WHO in 2012, South East Asia region showed higher occurrence and mortality than America, Africa, and Europe region. Based on the same data, also reported that the annual occurrence of oral cancer was 103,464 cases and the annual mortality rate was 25,202 . $^{1}$ More than $90 \%$ of oral cancers are oral squamous cell carcinomas (OSCC). Currently the oral cancer ranks sixth from all cancers on the human body. ${ }^{2-4}$

Reports from various countries shown that there are variations in the ratio of males to females and the age average of OSCC patients. Most countries reported more OSCC were found on male. ${ }^{1,2,5}$ Rao et al.${ }^{4}$ compared the research report in several Asian countries between the years 20002012 and found that the ratio of males to females varied between $6: 1$ to 1.45 . OSCC risk increases along with age. Oral squamous cell carcinoma is found mostly in the age of $5^{\text {th }}$ to $7^{\text {th }}$ decade. Warnakulasurya et al. ${ }^{2}$ and Feller et al. ${ }^{6}$ reported that the average age of OSCC patients in the United States in the period of 2000-2004 was 62.0 years of age. Results analysis of national data from 19752012 in England by Purkayastha et al. ${ }^{7}$ showed that the age average was 63.8 years of age. OSCC patients age average in most Asian countries were younger than in the U.S. and the U.K. which was between 51-55 years of age. ${ }^{4}$ Variations of gender and age of the OSCC patient is caused by several factors such as another different instrumental risk factors, lifestyle and culture.

The risk factors and lifestyle also cause different reports about the anatomic location of OSCC from country to country. Lingual part, especially two-third of the posterior, was the most anatomic location of OSCC in the United States and Europe which was $40-50 \%$ from all oral cancer. ${ }^{2,5}$ Reports from several Southeast Asian countries shown that the buccal mucosa and gingival were other most location of OSCC after lingual part. ${ }^{2,3,8}$ Other anatomic location of OSCC was labial part, especially the lower labial, due to sunlight exposure. ${ }^{9}$

The objective of this research was to get the epidemiologic profile, anatomic location, and histology of oral squamous cell carcinoma (OSCC) in Yogyakarta, Indonesia.

\section{METHODS}

The research method was observational analytic with cross-sectional design. All new OSCC cases in Yogyakarta (Indonesia) during the period of January 2011-December 2015 were included in this study. OSCC cases data were collected from 3 anatomic pathology laboratory installations, which was Dr. Sardjito Regional Public Hospital, Faculty of Medicine Universitas Gadjah Mada, and Cito Anatomic Pathology Laboratory. Data collected were gender, age, anatomical location, and histology. OSCC histology distinguished according to Border classification which were, well-differentiated, medium differentiated, and poor differentiated squamous cell carcinomas.

All data were analyzed using statistical analysis program. Continuous data were presented as mean \pm standard deviation, whilst categorical data were presented in the form of the number (n) and percentage (\%). Student $t$ test was conducted to determine the mean difference between two groups. Chi square test was conducted to analyze the relationship between two variables such as anatomic location and age, anatomic location and gender, anatomical location and histology. Significant value was $p<0.05$.

\section{RESULTS}

The total amount of OSCC cases from all three anatomic pathology installation was 91 cases. Table 1 illustrates the OSCC patient profile over the period 2011-2015. From data collected shown that there were 6 OSCC cases in 2011 and further increased into 32 cases in 2014 and became 24 cases in 2015. Male patients were more than female. The most anatomic location of OSCC was on the lingual part (46 cases, 55.4\%), and the histology mostly found were well differentiated (68 cases, $74.7 \%$ ).

Figure 1 showed the distribution of OSCC patients based on years of diagnosis by comfirmation of histopathologic examination. There was significant difference in the number of OSCC patients per year between male and female patients $(p=0.031)$. Figure 2 showed the distribution of anatomic location of OSCC based on gender. The most common anatomic sites in male group were tongue and palate 
Table 1. OSCC patients profile during the period of 2011-2015

\begin{tabular}{llcc}
\hline & & $\mathrm{n}$ & $\%$ \\
\hline Year & 2011 & 6 & 6.6 \\
& 2012 & 13 & 14.3 \\
& 2013 & 16 & 17.6 \\
& 2014 & 32 & 35.2 \\
& 2015 & 24 & 26.4 \\
\hline Gender & Male & 52 & 57.1 \\
& Female & 39 & 42.9 \\
\hline Anatomic Location & labial & 7 & 7.7 \\
& Lingual & 48 & 52.7 \\
& Gingival & 6 & 6.6 \\
& Palatum & 11 & 12.1 \\
& Buccal mucosa & 19 & 20.9 \\
\hline Histopathologic features & Well-Differentiated & 68 & 74.7 \\
& Medium differentiated & 18 & 19.8 \\
& Poor differentiated & 5 & 5.5 \\
\hline
\end{tabular}

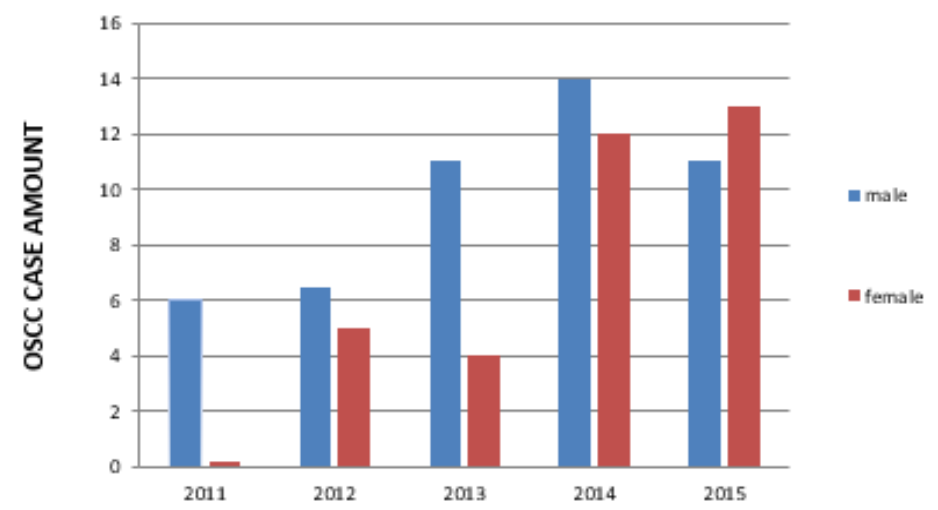

Figure 1. The distribution of OSCC patients based on gender and year of diagnosis was established by histopathological examination. There was a significant difference in the annual amount of OSCC patients between male and female $(p=0.031)$

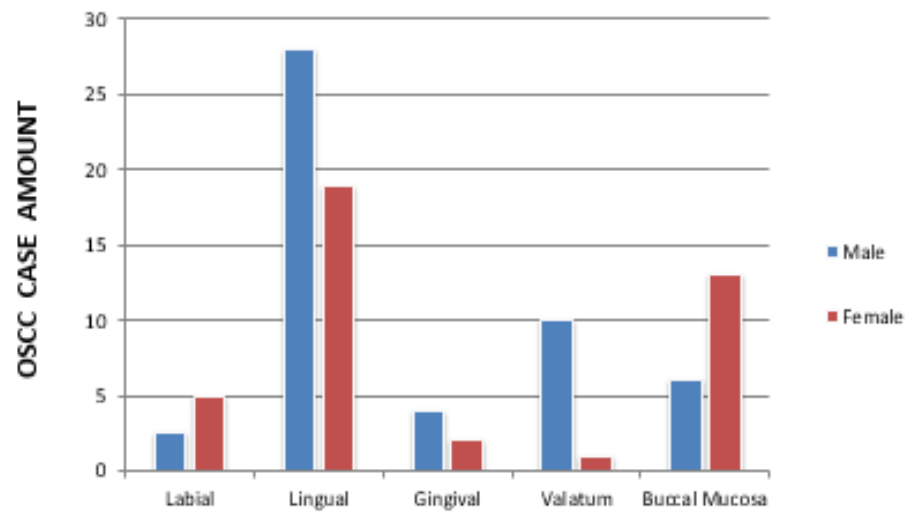

Figure 2. The OSCC anatomic location distribution based on gender. Most anatomic location on the male group was the lingual and palatum part (29 cases and 10 cases), whilst on the female group was the lingual and buccal mucosa part (19 cases and 12 cases) 
Table 2. OSCC patients age profile

\begin{tabular}{|c|c|c|c|c|c|c|c|}
\hline & \multicolumn{6}{|c|}{ Age } & \multirow{3}{*}{ P-value } \\
\hline & \multicolumn{2}{|c|}{$\leq 40$} & \multicolumn{2}{|c|}{$41-60$} & \multicolumn{2}{|c|}{$\geq 61$} & \\
\hline & $\mathrm{n}$ & $\%$ & $n$ & $\%$ & $n$ & $\%$ & \\
\hline Male & 8 & 15.4 & 29 & 55.8 & 15 & 28.8 & 0.379 \\
\hline Female & 8 & 20.5 & 16 & 41.0 & 15 & 38.5 & \\
\hline Total & 16 & 17.6 & 45 & 49.5 & 30 & 33.0 & \\
\hline
\end{tabular}

Table 3. Relation between OSCC anatomic location, gender, age, and histopathological feature

\begin{tabular}{|c|c|c|c|c|c|c|c|}
\hline & \multicolumn{4}{|c|}{ OSCC anatomic Location } & \multicolumn{2}{|c|}{ Total } & \multirow[t]{2}{*}{ P-value } \\
\hline & \multicolumn{2}{|c|}{ Lingual } & \multicolumn{2}{|c|}{ Non lingual } & \multirow[b]{2}{*}{$\mathrm{n}$} & \multirow[b]{2}{*}{$\%$} & \\
\hline & $\mathrm{n}$ & $\%$ & $\mathrm{n}$ & $\%$ & & & \\
\hline \multicolumn{8}{|l|}{ Gender } \\
\hline Male & 30 & 61.2 & 22 & 52.4 & 52 & 57.1 & 0.406 \\
\hline Female & 19 & 38.8 & 20 & 47.6 & 39 & 42.9 & \\
\hline \multicolumn{8}{|l|}{ Age } \\
\hline$\leq 40$ Year & 12 & 24.5 & 4 & 9.5 & 16 & 17.5 & $0.035^{*}$ \\
\hline 41-60 Year & 26 & 53.1 & 19 & 45.2 & 45 & 49.5 & \\
\hline$\geq 61$ Year & 11 & 22.4 & 19 & 45.2 & 30 & 33.0 & \\
\hline \multicolumn{8}{|l|}{ Histopathologic features } \\
\hline Well-Differentiated & 38 & 55.9 & 30 & 44.1 & 68 & 74.7 & 0.629 \\
\hline Medium differentiated & 11 & 47.8 & 12 & 52.2 & 23 & 25.3 & \\
\hline
\end{tabular}

Note: ${ }^{\mathrm{p}} \mathrm{p}$-value $<0.05$

(Consecutively 29 cases and 10 cases) where in female group were mosfly found in tongue and buccal mucosa (Consecutively 19 cases and 12 cases) in Table 2 showed the age average of the group of patients on this research was $54.1 \pm 13.6$ (age range 23-84 years). The age average of the male group was $53.4 \pm 1.7$ and $55.1 \pm 2.5$ of female group. The youngest and oldest age on the male group consecutively was 23 years and 75 years, whereas on the female group consecutively was 26 years and 84 years. There were no significant differences in age average between male and female. Statistical analysis was then performed by grouping the age into several categories: age $\leq 40$ years, 41-60 years and $\geq 61$ years. In Table 2 shown the largest distribution by age was found in the category of $41-60$ years $(49.5 \%)$. Bivariate analysis on chi square test were conducted to determine the relationship between the OSCC anatomic location and gender, and also between the age and OSCC histopathological feature. Significant relationships with $\mathrm{p}<0.05$ were found only between the OSCC anatomic location and age (Tab. 3).

\section{DISCUSSION}

Oral squamous cell carcinoma is a type of oral cancer mostly reported. Data taken from many countries shown that there are increasing number of this type of cancer. Total OSCC cases data collected during the period of 2011-2015 from 3 anatomic pathology laboratory in Yogyakarta were 91 cases in the different anatomic location.

Oral squamous cell carcinoma were mostly found in male than female, as found from the research conducted in Yogyakarta during the period of past 5 years with the ratio of male to female was 1.3:1. Similar results were reported in 2016 from Hernandez-Guerrera et al. ${ }^{10}$ research, that stated the ratio of male to female OSCC patients was 1.4:1. Several other researchers reported that the ratio of male to female was higher than the research result in Yogyakarta, such as in Brazil, 
during the period of 2005-2012 the ratio was 2.0:1 (total 346 cases); in Italy, during the period of 2000-2005 the ratio was 2.4:1 (total 156 cases); in Central India, during the period of 2008-2010 the ratio was 4.1:1 (total 295 cases); and in North India, during the period of 2010-2013 the ratio was 3.1: 1 (total 611 cases). ${ }^{3,5,8,11}$ The factors that cause the high prevalence on male patients were smoking habit, alcohol consumption, and sunlight exposure. ${ }^{2}$

Warnakulasurya et al. ${ }^{2}$ reported that there were decreasing of the male patient amount in the past few years, so male to female ratio became 1.5:1. This ratio changes also reported by Zhang et al. ${ }^{12}$ based on data taken during the period of 1960-2013 in China. Male to female ratio in China during the period of 1960-1973 was 2.11:1 and decreased to $1.83: 1$ during the period of 20002013. ${ }^{12}$ Purkayastha et al. ${ }^{7}$ reported that there was a tendency of escalation in female OSCC patients amount in England. Data taken from 3 anatomic pathology installation in Yogyakarta also shown that during the period of 2011-2015 the amount of OSCC male patient remains high, whilst on female patient found increase tendency ( $p$ value $=0.039$ ). The increase of risk factors exposure, such as smoking habit, alcohol consumption, and sunlight exposure, considered being the main cause in the increasing amount of OSCC female patients in some countries. ${ }^{12}$

Oral squamous cell carcinoma mostly found on elderly people (range 50-70 years). ${ }^{2,6}$ Patients age average in this research was $54.1 \pm 13.6$ with no age average difference between male and female group (male $53.4 \pm 1.7$; female $55.1 \pm 2.5$ ). The overview of age average in this research was different than the two researches from India which reported that the age average was 49.7 years and there was significant difference between male and female group $(46.9 \pm 13$ men, women 52.8 $\pm 12.1) .{ }^{3,8}$ The majority of OSCC patients, both male and female, were included in the 41-60 years of age category. In some countries reported that there was an increasing tendency on OSCC patients aged less than 45 years with unknown cause. 3,6 The high percentage of patients that included to the 41-60 years age category in this study showed no change in the age profile of OSCC patients in Yogyakarta.
The lingual part was the mostly reported OSCC anatomic locations around the world and allegedly associated with smoking habit and alcohol consumption. ${ }^{2,4,6,9}$ Shenoi et al. ${ }^{3}$ and Singh et al. ${ }^{8}$ reported that the habit of betel quid consumption in India led to the high prevalence of OSCC on the buccal mucosa, gingival sulcus and the alveolar mandibular. anatomic locations The labial part was rarely reported OSCC anatomic locations in Asian countries. ${ }^{4}$ Forty-nine out of 91 OSCC cases in Yogyakarta found at the lingual part (53.8\%), the buccal mucosa part (20.9\%) and the palatum part $(12.1 \%)$. This result showed that the distribution of the OSCC anatomic location in Yogyakarta during the period of 2011-2015 was almost the same as in the Asian countries.

Del Corso et al. ${ }^{9}$ research shown that in the past 20 years there was an increasing amount of tongue cancer cases in young patients aged less than 45 years with no smoking habit and alcohol consumption. Whilst Zini et al. ${ }^{13}$ reported on male group of OSCC patients, the anatomic location found in two-thirds of the anterior lingual part $(81 \%)$, whereas the group of female mostly found in the lateral lingual part (78.5\%).

Table 3 showed that the predominant anatomic location of OSCC in the male group was is on the lingual part, whereas in the female group was on the outer side of the lingual part. Oral squamous cell carcinoma on the lingual part in Yogyakarta mostly found in the 41-60 years of age category. The age distribution of OSCC patients on the lingual part was different from the research of Sutandyo et al. ${ }^{14}$ which stated that the majority of patients with tongue cancer in the Dharmais Cancer Hospital Jakarta included in 31-40 years of age category.

The results of histologic examination showed 46 cases $(78 \%)$ were well-differentiated carcinoma, 11 cases $(18.6 \%)$ were moderately differentiated, and 2 cases $(3.4 \%)$ were poor differentiated (Table $3)$. There was no significant relationship between the distribution of histological feature with other variables in the study (age, gender, anatomic location). Histological feature in this research was different from the results of Hernandez-Guerrero et al..$^{10}$ research which reported that a medium differentiated histological picture was more prevalent in OSCC on the lingual part. 


\section{CONCLUSION}

OSCC patients profile in Yogyakarta mostly found in men with anatomical location in the lingual part in the age group above 40 years of age and were having well-differentiated histology.

\section{REFERENCES}

1. Rivera C. Essential of oral cancer. Int J Clin Exp Pathol 2015;8(9):11884-94.

2. Warnakulasuriya S. Global epidemiology of oral and oropharyngeal cancer. Oral Oncol 2009;45(4-5):309-16.

3. Shenoi R, Devrukhkar V, Bk S, Sb S, Chikhale A. Demographic and clinical profile of oral squamous cell carcinoma patients: A retrospective study. Indian J Cancer 2012;49(1):21-6.

4. Rao SVK, Mejia G, Roberts-Thomson K, Logan $R$. Epidemiology of oral cancer in Asia in the past decade-An update (2000-2012). Asian Pacific J Cancer Prev 2013;14:5567-77.

5. Pires FR, Ramos AB, De Oliveira JBC, Tavares AS, Luz PSR Da, Dos Santos TCRB. Oral squamous cell carcinoma: clinicopathological features from 346 cases from a single oral pathology service during an 8-year period. J Appl Oral Sci 2013;21(5):460-7.

6. Feller L, Lemmer J. Oral squamous cell carcinoma: epidemiology, clinical presentation and treatment. J Cancer Ther 2012;3(Aug) :263-8.

7. Purkayastha M, MCMahon AD, Gibson J, Conway DI. Trends of oral cavity, oropharyngeal and laryngeal cancer incidence in Scotland (19752012)-A socioeconomic perspective. Oral Oncol. 2016;61:70-5.

8. Singh MP, Kumar V, Agarwal A, Kumar R, Bhatt MLB, Misra S. Clinico-epidemiological study of oral squamous cell carcinoma: A tertiary care centre study in North India. J Oral Biol Craniofacial Res 2016;6(1):32-5.

9. Del Corso G, Villa A, Tarsitano A, Gohel A. Current trends in oral cancer: A review. Cancer Cell Microenviroment 2016;3:1-11.

10. Hernández-Guerrero JC, Jacinto-Alemán, LuísFernando, Jiménez-Farfán, María-Dolores, Macario-Hernández, et al. Prevalence trends of oral squamous cell carcinoma; Mexico City' S General Hospital experience. Med Oral Patol Oral Cir Bucal 2013;18(2):7-12.

11. Panzarella V, Pizzo G, Calvino F, Compilato D, Colella G, Campisi G. Diagnostic delay in oral squamous cell carcinoma: the role of cognitive and psychological variables. Int $\mathrm{J}$ Oral Sci 2014;6(1):39-45.

12. Zhang J, Gao F, Yang AK, Chen WK, Chen SW, Li $\mathrm{H}$, et al. Epidemiologic characteristics of oral cancer: Single-center analysis of 4097 patients from the Sun Yat-sen University Cancer Center. Chin J Cancer; BioMed Central 2016;35(4):1-6.

13. Zini A, Czerninski R, Sgan-Cohen HD. Oral cancer over four decades: Epidemiology, trends, histology, and survival by anatomical sites. J Oral Pathol Med 2010;39(4):299-305.

14. Sutandyo N, Ramli R, Sari L, Soeis DS. Profile and survival of tongue cancer patients in Dharmais Cancer Hospital, Jakarta: Asian Pacific J Cancer Prev 2014;15(5):1971-5. 